\title{
Complete Internal Penile Auto-Amputation
}

\section{Crockett MG* and Hill G}

Southmead Hospital, Bristol, UK

Received: May 31, 2018; Published: June 13, 2018

*Corresponding author: Matthew G. Crockett, Bristol Urological Institute, Level 3, Learning and Research Building, Southmead Hospital, Bristol BS10 $5 \mathrm{NB}, \mathrm{UK}$

\section{Case Report}

We report the bizarre case of a young man who severed his penis in an industrial accident. What makes this case unique is that the injury occurred subcutaneously. On September 4th, 2017 a 24 year old, otherwise fit and healthy young man, was brought by ambulance to the emergency department (ED) in Southmead Hospital, Bristol. The unfortunate gentleman had been working on a building site with a handheld circular saw. The tool had become caught in his shorts and propelled itself into the right side of his groin. He was seen by the ED doctors who provided analgesia and a tetanus shot and immediately referred to the on-call Urologist. Upon initial assessment, the patient was cardiovascularly stable but in significant pain with heavy bleeding from his groin wound. Accurate assessment of his wound was limited by his pain but it was possible to determine that there was a complete penile transection (Figures 1-3) and that the force of the saw had pulled the distal portion of his penis (which was ischaemic and insensate) through the groin wound which was hanging at the level of his knees suspended by his inverted penile skin.

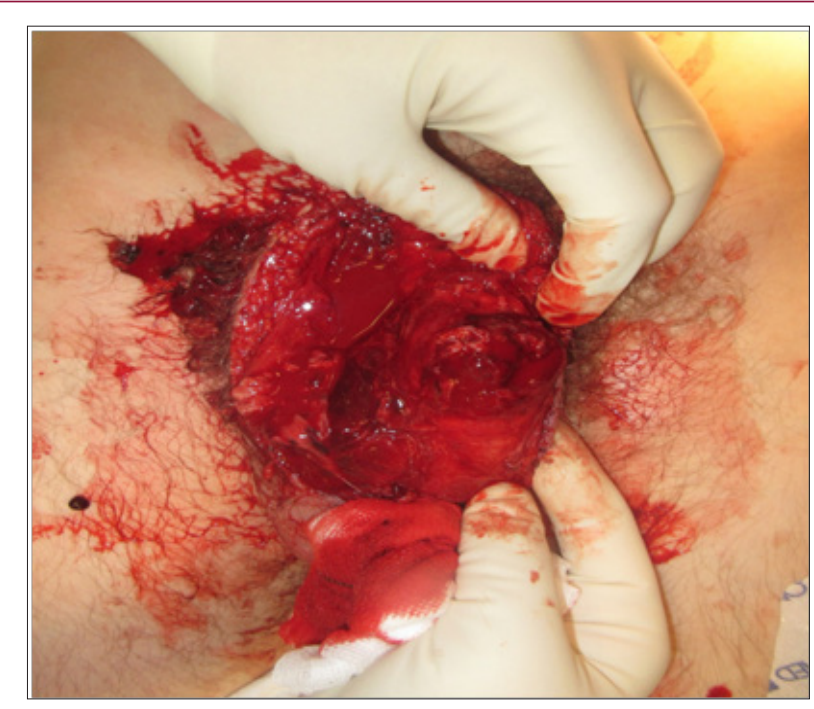

Figure 1: Photograph showing proximal part of completely transected penis.
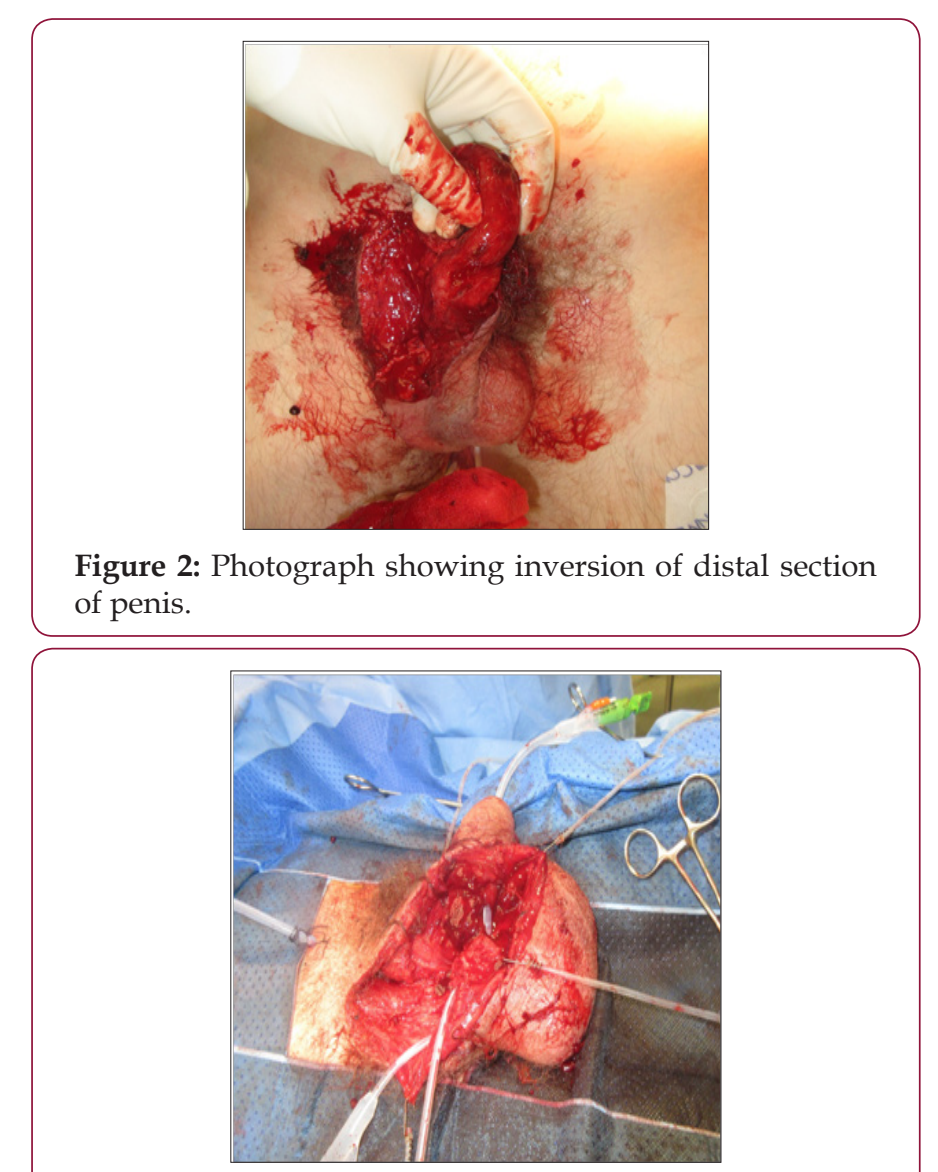

Figure 3: Photograph showing suprapubic and urethral catheter placement. The distal urethral segment is marked with a white arrow.

In the operating theatre we discovered that the saw had entered $5 \mathrm{~cm}$ to the right of the midline, just above his inguinal ligament and at an angle of around $45^{\circ} \mathrm{C}$. It had torn the tunica vaginalis of his right testis, narrowly missed his femoral vessels and had only scored his pubis. It had, however, completely transected his corpora cavernosa and urethra in an oblique fashion. The wound was actually very clean but was washed and devascularised tissue 
debrided. The majority of the bleeding was from the dorsal penile arteries and a tourniquet was tied around the proximal stump. A $16 \mathrm{Fr}$ catheter was passed from the meatus and then passed through from the distal to proximal parts of his divided urethra which helped define the anatomy and allowed us to leak test the bladder. The corporal arteries were clipped and the corpora cavernosa were anastomosed using interrupted 3-0 PDS sutured. The urethra was spatulated and anastomosed over the catheter using continuous 4-0 Vicryl, excess urethral tissue was wrapped around the suture line to improve the seal. The bladder was repaired with 3-0 vicryl in two layers and a suprapubic catheter was placed away from the external wound. This was all completed by the on-call Urologist.

The Plastics team were then asked to assess the possibility of microsurgical repair. Due to the sharp nature of the wound they were able to identify and mobilise the dorsal veins (superficial $\&$ dorsal), arteries and nerves (one on each side). The maximum diameter of these vessels is less than $2 \mathrm{~mm}$ and their fragility led to multiple tears. However, after multiple patient attempts we successfully repaired one vein and both nerves using 9-0 Ethilon and both arteries using 10-0 Ethilon and an operating microscope. In total the operation took around eight hours with around six hours of ischaemia time since the injury. The patient was placed on heparin and antibiotic prophylaxis and made an excellent early recovery. Capillary refill was consistently good and flow was confirmed on Doppler each day. He regained patchy sensation in his penile shaft skin and glans within 48 hours and continued to improve to almost normal sensation at nine months. A pericatheter urethrogram was performed 12 weeks later and showed no leak and his urethral catheter was successfully removed, shortly followed by the suprapubic catheter. The patient refused a postoperative flow test but reports a good flow rate with no straining and only some minimal terminal dribbling. His erections have also returned with an IIEF-SF score of 19 (overall satisfaction 4 out of 5). At 9 months post-operatively his erections are subjectively shorter, less rigid and deviated to the left but he is able to have satisfactory intercourse without buckling and reach a successful orgasm. He has not developed any other complications (stricture, fistula, skin necrosis).

Penile amputation is uncommon and the lack of high quality evidence prevents a standardised approach. Various outcomes have been reported in solitary case studies or small series but due to the significant psychological, physical and sexual burden associated with penile amputation, emergency repair should be attempted. Isolated accidental amputation is rare being responsible for only around $20 \%$ of amputations [1-2]. The most common aetiologies are self-inflicted (Klingsor syndrome), domestic violence and iatrogenic (such as during circumcision). Historically, replantation was rarely attempted and some patients were even encouraged to change gender [3]. The first penile replantation was described by [4] who realigned the corporal bodies without neurovascular anastomosis. Microneurovascular repair was not reported until 1977 [5] and created a paradigm shift in approach due to the ability to improve outcomes, not just for erectile function, but also sensation of the penis. The largest published series of 18 patients is from Thailand in 1983 after an epidemic of retribution amputations from philandering husband's wives [6]. The authors state that microsurgical repair would have improved outcomes but they lacked the equipment, time and training. Despite this 50\% achieved a satisfactory erection (many lost to follow up).

In 2007, Babaei et al reported a systematic review including 80 patients undergoing replantation, 30 of whom had microneurovascular repair [7]. They concluded that microsurgical repair reduced complications (fistula, stricture formation, skin necrosis, sensory loss \& erectile dysfunction) and improved graft survival and cosmetic outcome. 27 of the 30 microsurgical cases were 'successful' although this was not defined. However, they also found that spontaneous erections and the ability to intromit with full sensation were very rare. In 2017, Morrison et al reported on 106 case reports of penile replantation with more positive findings [2]. $91.6 \%$ had 'overall satisfaction' although this is not clearly defined (see Table 1 for all outcomes and complications). Improved outcomes correlated with the number of nerves anastomosed and decreased with the number of vessels anastomosed (presumably due to increased ischaemia time). However, repair of the superficial dorsal penile artery was strongly recommended and successful replantation has been reported with an ischaemic time of 15 hours [8].

Table 1: Outcomes and complication rates for microsurgical penile replantation [2].

\begin{tabular}{|c|c|}
\hline Overall satisfaction & $91.6 \%$ \\
\hline Full sensation & $68.4 \%$ \\
\hline Adequate urinary function & $97.4 \%$ \\
\hline Normal erection & $77.5 \%$ \\
\hline Skin necrosis & $54.8 \%$ \\
\hline Venous congestion & $20 \%$ \\
\hline Urethral stricture & $11 \%$ \\
\hline Urethrocutaneous stricture & $6.6 \%$ \\
\hline
\end{tabular}

\section{Conclusion}

In conclusion, our patient had a fantastic outcome from his surgery with no complications at nine months. This was due in part to the nature of his injury, lack of co-morbidities, relatively short ischaemic time, excellent microneurovascular repair and postoperative care. Expedient surgery with microneurovascular repair should be considered the gold standard management for penile amputation.

\section{References}

1. Jezior JR, Brady JD, Schlossberg SM (2001) Management of Penile Amputation Injuries. World Journal of Surgery [Internet]. Springer Nature 25(12): 1602-1609.

2. Morrison SD, Shakir A, Vyas KS, Remington AC, Mogni B, et al. (2017) Penile replantation: A Retrospective Analysis of Outcomes and Complications. J Reconstr Microsurg 33(4): 227-232.

3. Krishnakumar KS, Kiran S Petkar, Sameer Lateef, Suresh Vyloppilli, et al. (2013) Penile replantation. Ind J Plastic Surgery 46(1): 143-146.

4. Ehrich WS (1929) Two Unusual Penile Injuries. The Journal of Urology [Internet]. Elsevier BV 21(2): 239-241. 
5. Cohen, May JW, Daly JS, Young HH (1977) Successful clinical replantation of an amputated penis by microneurovascular repair. Case report. Plast reconstr Surg 59(2): 276-280.

6. Bhanganada K, Chayavatana T, Pongnumkul C, Tonmukayakul A, Sakolsatayadorn P, et al. (1983) Surgical management of an epidemic of penile amputations in siam. The American Journal of Surgery 146(3): 376-382.

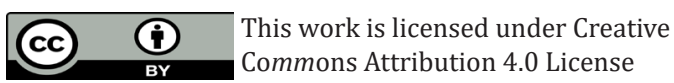

Submission Link: https://biomedres.us/submit-manuscript.php
7. Babaei AR, Safarinejad MR. (2007) Penile replantation: Science or Myth? A systematic review. Urol J 4: 62-65.

8. Ozturk A, Kilinc M, Guven S (2009) Penis replantation after selfmutilation. Int Urol Nephrol 41(1): 109-111.

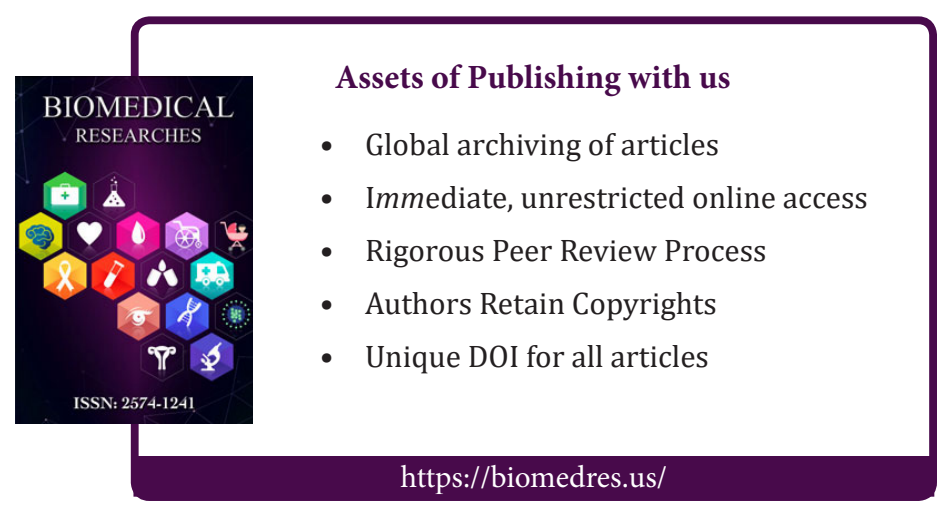

